\title{
A TRAJETÓRIA DE UM REPUBLICANO (ALBERTO TORRES) $\left(^{\star}\right)$.
}

\author{
ADALBERTO MARSON \\ Disciplina: História Contemporânea.
}

\begin{abstract}
"A vida dos homens que atravessam crises revolucionárias é toda feita, igualmente, de revoluções pessoais. Só quem haja acompanhado, dos primeiros movimentos a seus últimos refluxos, os to:velinhos de uma época crítica, poderá conhecer e avaliar os abalos que a desordem geral vem produzindo em nossos destinos."
\end{abstract} sileiro)

(Alberto Torres - O problema nacional bra-

O propósito deste artigo não é retratar todas as vicissitudes da carreira política de Alberto Torres, uma porque essa seria tarefa mais própria de uma biografia, e outra porque este assunto pode ser devidamente examinado nas obras do gênero, especialmente na de Barbosa Lima Sobrinho, que é a mais completa (1). Nem muito menos se trata de contrapor à sua trajetória individual uma história dos acontecimentos, das transformações e das situações por ele vividos, ou das pessoas e grupos a ele vinculados. De preferência, procuro acompanhar os passos de um político republicano, desde a fase de propaganda e construção do novo regime, até a instalação e consolidação, chegando a fase em que este político se define nos papeis de oposição. Nestes momentos decisivos, serão captados os traços característicos de sua proposta ideológica e participação política que permitem localizar a transformação de um programa liberal-popular em um programa liberal-nacional.

(*). - Este artigo faz parte de uma investigação mais ampla sobre $A$ ideologia nacionalista em Alberto Torres, para elaboração de Tese de Doutoramento, sob orientação do Prof. Carlos Guilherme Mota, na área de História Social.

(1). - LIMA Sobr. (Barbosa), Presença de Alberto Torres. Rio de Janeiro, Civilização Brasileira, 1968. 
Já nos tempos em que frequentou a Faculdade de Direito de São Paulo (1882 a 1884), Alberto Torres envolveu-se na propaganda republicana e abolicionista que se alastrava no meio acadêmico, através de jornais, clubes republicanos, conferências e discussões. Conquanto não se tenha destacado entre os líderes estudantis, nem deixado colaborações propriamente políticas nesses pequenos jornais - onde escreveu frequentemente poesias e crônicas literárias - , chegou a integrar o corpo de redatores do orgão principal do clube republicano acadêmico, $A$ República, fundado em 1876. Suas convicções republicanas e abolicionistas alicerçaram-se nesta fase, pois constituiam a própria natureza da vivência estudantil, cuja disponibilidade e descompromisso com funções profissionais diretas permitiam aliar ociosidade e a vida boêmia às utópicas inquietações políticas.

Muito mais tarde, quase no fim de sua existência, Alberto Torres recordaria esses tempos de sua jeunesse dorée, lembrando essas fervorosas e difusas aspirações republicanas que alimentavam os debates acadêmicos e a convivência nas "repúblicas" estudantis.

“... Havia no borborinho e na agitação daquellas 'repúblicas' a vida forte e potente do embate e da vibração do pensamento, sobre a matéria sólida das coisas. Não sabíamos, seguramente, o que era Liberdade, mas aspirávamos a libertação dos negros e a Democracia...

A Republica quase nos não dizia fórmulas de logomachia constitucional; mas (...) prenunciava-nos um povo, uma gente, - cidades e campos alegres e prósperos; os seres amigos, na comunidade de um zelo e de um esforço solidário, - ricos, alguns, mas todos contentes, da alegria máscula e boa que trazem os sorrisos os que se fazem, lavrando a saúde, a inteligência e o caráter, com o trabalho das mãos, na terra, e com o esforço tenaz do sentimento e do raciocínio nos cérebros" (2).

Transferindo-se para a Faculdade de Direito do Recife, em 1885, ali concluiu o curso de advocacia. De volta ao Rio de Janeiro, entrega-se à atividade política e jornalística, muito mais do que ao exercício de sua profissão, para a qual não tinha temperamento adequado, e que desempenhou precariamente, embora não lhe faltassem meios de realização. Seu pai, Manuel Martins Torres, juiz de Direito, era político influente, chefe do Partido Liberal local, podendo facilitar-lhe a clientela e cargos na magistratura. Por outro lado, desfrutava de um círculo de amizades com advogados estabelecidos, chegando a filiarse a um escritório famoso na Corte, dirigido por Ubaldino do Ama-

(2). - Saudades Murchas, O Estado de São Paulo, 9/8/1916, p. 3. 
ral. Em vez da advocacia, empenhou-se muito mais em escrever matérias para vários periódicos do Rio de Janeiro, aumentando paulatinamente seu compromisso com a propaganda republicana e abolicionista. Em meados de 1888, vincula-se ao grupo de Silva Jardim, cooperando na organização do Partido Republicano Fluminense, ao lado de Limpo de Abreu, Carr Ribeiro e outros, e na aglutinação de clubes republicanos pelo interior da Província. Nos quadros da seção provincial do Partido, ocupa o cargo de Secretário da Comissão Executiva.

O período que vai de meados de 1888 até a proclamação da República marcou intensamente a participação política de Alberto Torres. Torna-se definidamente um dos construtores do regime republicano, pela ação política e jornalística. Juntamente com Carr Ribeiro integra a redação do jornal republicano $O$ Povo, cujo primeiro número saiu em Niteroi, em julho de 1889. Acompanhando a rápida ascensão das forças republicanas na província fluminense, candidata-se a deputado à Assembléia Geral, pelo 4. ${ }^{\circ}$ Distrito, compartilhando da derrota que sofreram seus companheiros no pleito de 1889 .

A ligação originária com Silva Jardim, solidificada inclusive por uma amizade pessoal, não significava uma concordância plena em termos de princípios doutrinários e posições táticas. O cerne desta divergência estava numa discordância quase que inconciliavel em torno da forma de governo republicano, distribuição e funções dos poderes, organização administrativa e autonomia das unidades federativas, mecanismos representativos, métodos de ação política transformadora, essa última a mais séria das questões, por envolver a base de apôio em grupos sociais. Esses pontos de divergência sintetizavam-se, em sua expressão mais reduzida, em certas polarizações consagradas quanto às formas de conceber um regime político, e já bastante difundidas nos debates da propaganda republicana: centralização administrativa $\mathrm{X}$ descentralização, parlamentarismo $\mathbf{X}$ presidencialismo, representação democrática ampla $X$ representação restrita, concentração $X$ descentralização de poderes, métodos revolucionários institucionais $\mathbf{X}$ meios revolucionários, via eleitoral $\mathrm{X}$ golpe político-militar, entre outros tipos de oposições.

Como não interessa aos propósitos deste artigo explorar mais a fundo a generalidade e o teor dessa divergência, mas apenas dizer o que toca de perto à trajetória de Alberto Torres, importa ressaltar o encaminhamento de sua divergência para uma solução caracteristicamente liberal democrática, com os seus corolários de ampla representatividade "popular", separação de poderes, descentralização administrativa, meios de ação graduais e dentro dos limites legais institucionais. Foi com base nesta opção que Alberto Torres travou acirrada polêmica 
com as teses de Silva Jardim e Anibal Falcão, na imprensa carioca, no decorrer do último ano da Monarquia, explicitando suas posições através de três idéias fundamentais:

"I. - Aspiro para o Bzasil, em substituição ao atual regime, um regime republicano democrático, em que a Nação delegará o poder Legislativo a deputados, que deliberarão, e o poder Administrativo ao Presidente do Conselho, que executará.

II. - A função legislativa competirá unicamente aos deputados. Os poderes Legislativo e Executivo serão distintos e independentes.

III. - As províncias do Brasil constitui ão uma Confederação republicana, no tipo dos Estados Unidos norteamericanos e da Colômbia" (3).

O desdobramento de sua opção liberal-democrática que, no fundo, ia de encontro à linha "moderada" da cúpula dirigente do Partido Republicano Federal (ala de Quintino Bocaiuva), com alguns pequenos reparos na intransigência abolicionista de Alberto Torres, aparece definida, enquanto viabilidade de ação política, através de seus escritos no periódico fluminense $O$ Povo e no programa apresentado por ocasião de sua candidatura a deputado, no pleito realizado em 31 de agosto de 1889. Na Circular dirigida ao "Cidadão Eleitor", faz-se representante do "protesto dos descrentes", "dos desiludidos", "dos desinteressados", contra a "ruina e o aviltamento da nossa querida Pátria", cujos direitos e interesses promete defender. A postura liberal define-se pela caracterização de uma "crise política" gerada pela ineficácia do regime monárquico em resolver os problemas e dificuldades de setores sociais diversos, e para a qual a única solução viavel seria a implantação da República, por meios eleitorais. Tratava-se, em poucas palavras, de encontrar uma solução institucional adequada à "sociedade brasileira", pois que a Monarquia resultava na criação de um "estado anômalo", criando "privilégios", "regalias", "desordens", e só atendendo a uma "camarilha limitada da sociedade".

"Tôdas as classes esmagadas pelo peso formidavel da monarquia: - o infeliz proletariado agrícola, sem instrução, inutilizado para o trabalho ou transformado em instrumento de desordem e de ódio de raça; o proletariado urbano, morto por falta de indústria; o comércio onerado de impostos exorbitantes,

(3). - Artigo publicado na Gazeta de Noticias. Apud Barbosa Lima Sobrinho, ob. cit., p. 81 . 
quase paralizado; os profissionais graduados forçados ao exercício quase gratuito das suas profissões; a lavoura arruinada por falta de braços e iludida pelos chefes monárquicos, que lhes p:ometem auxílios e reparações que não podem e não pretendem realizar; o funcionalismo enfim, mal remunerado, sujeito a injustiças constantes e subjugado inquisitorialmente, na liberdade de consciência, de pensamento e de voto, até a desfaçatez extrema da imposição da adesão ao governo sob a pena de demissão, isto é, de miséria para a família $(. .$.$) .$

A par disso, uma dívida extrema fabulosa - dívida de origem po tuguesa, que a família Bragança ros fez encampar; a divida interna tambem grande, a juros baixos (em relação aos juros da nossa praça) e depreciada; o capital paralizado por falta de meios de emprego; e o esbanjamento de dinheiros públicos em garantias de juros quase sempre improfícuas, em indenizações exigidas tiranicamente pelas naçõe $e_{S}$ estrangeiras, em subvenções pesadas, em emp:eitadas eleitorais, enfim (...)" (4).

Republicano da ordem, reformador inspirado pelo estudo "calmo e despido de paixões e preconceitos" da situação política do momento, conclama os "cidadãos criteriosos e refletidos", os "cidadãos eleitores republicanos", os "patriotas", a resolverem pela solução pacífica do "voto" a crise político-institucional da "nação" que se traduzia num impasse: o terceiro reinado, ou a "emancipação à custa de enormes sacrifícios, numa convulsão revolucionária, de tempo, de anarquia, de dinheiro e de sangue".

“( ...) Com a manifestação anterior do protesto, com o prestígio previamente adquirido e com a arregimentação de suas forças, os patriotas terão adquirido um consideravel valor, capaz de fazer recuar o príncipe francês ou de vencer sem dolorosas perturbações.

Para isto basta a revolta de cada cidadão contra os atos viciosos dos partidos até hoje militantes, os compromissos pessoais, a influência perniciosa dos chefes locais; às claras, quando o puder fazer ou na conspiração pacífica do voto, quando preso por conveniência de qualquer ordem" (5).

A defesa dos "direitos do cidadão" e a ênfase na mudança do regime para conciliar o Estado com a sociedade civil centralizam a es-

(4). - Circular ao Cidadão Eleitor, $O$ Povo, 23/8/1889, publicada por Dalmo Barreto, Alberto Torres, sociologo e jornalista. Niteroi, Imprensa Oficial, 1970. pp. 89-93.

(5). - Idem, ibidem, p. 92. 
sência do programa liberal-popular apresentado por Alberto Torres nesta fase, onde a República é sinônimo de "ordem" e "progresso", e os direitos civis são identificados às reais necessidades do conjunto da sociedade brasileira. Com esta orientação entusiasmada devotou grande atenção à ação jornalística, confiante no poder da palavra. O periódico $O$ Povo, onde teve acentuada liderança, destinava-se a efetivar esse tipo de pregação, definindo seu programa no primeiro número (29 de julho de 1889):

“... Defender e dirigir o povo, zelar pelos seus direitos de comunidade e pelos direitos pessoais de cada um dos indivíduos que o compõem - eis a nossa pretenção.

(...) Coerentes com a nossa atitude de advogado da sociedade e dos cidadãos, combateremos, no terreno político, pelo ideal republicano, pelo governo em que o povo nomeia os diretores do povo, pelo advento do único regime compativel com a evolução americana e com as tradições da História Brasileira, onde a vida da monarquia representa um capítulo acidental e ilógico. A República é o governo normal das sociedades civilizadas, é o estado de perfeita autonomia social, é o regime das forças nacionais para o progresso, dentro da ordem" (6).

Sistematizando, constata-se que o programa liberal-popular apoia-se em três premissas conceituais, articuladas entre si: povo-sociedadenação. Nesta cadeia, o conceito de povo, pela sua própria generalidade, opera como catalizador da ação política e esgota o alcance da proposta ideológica. Quer dizer, a crítica liberal-republicana circunscreve-se aqui à esfera jurídico-política, começa e termina no campo dos direitos civis e políticos dos cidadãos, desenvolvendo a tese central do "povo desgovernado". Por isso, na sua demonstração justificadora e na correspondente prática política, o programa defendido por Alberto Torres concentra sua atenção nas questões referentes à forma de governo, representatividade e legitimidade de poder. $\mathrm{O}$ que está em jogo não é a estrutura e a natureza da organização social, nem mesmo a existência em si da "sociedade civil", mas a ausência de meios e aparelhos institucionais representativos, adequados e legítimos. No máximo, chega a localizar agrupamentos sociais profissionais, diferenciados e heterogêneos, definidos basicamente pela formação de seus "interesses" em problemas políticos; daí a divisão da sociedade em grupos "privilegiados" e grupos "prejudicados", de acordo com as suas respectivas posições políticas dentro dos estreitos e hierárquicos mecanismos representativos do regime monárquico. p. 63 .

(6). - O Povo, 29/7/1889, Apud, Barbosa Lima Sobrinho, ob. cit., 
Proclamada a República e instalados os novos grupos dirigentes, Alberto Torres entrou no exercício de cargos e funções de poder de diferentes níveis e natureza, mantendo-se irredutivel na defesa do regime e assumindo os papeis característicos da posição governista. Entre os anos de 1889. e 1900, ocupou os cargos de: Deputado Estadual (1892-1893), Deputado Federal (1894-1896), Ministro da Justiça (agosto de 1896 - janeiro de 1897), Presidente do Estado do Rio (1897-1900). Nestas funções, foi mais destacada sua atuação no âmbito da política fluminense (como Deputado e Presidente), pois na Câmara Federal participou discretamente dos debates, concentrando seus esforços em trabalhos de Comissões, e no Ministério da Justiça sua passagem foi curta e provisória (mandato interino), demitindo-se imediatamente após o afastamento do Presidente da República, Prudente de Morais.

Verificando sua presença nos Anais da Assembléia Legislativa do Rio de Janeiro, de 1892 a 1893, destaca-se a figura de um orador versatil, polemista convincente, bastante informado das sutilidades jurídicas do direito constitucional, e, acima de tudo, personificando o governo e o regime republicano. Como lider da maioria, numa Assembléia inteiramente da situação, desempenhou papel relevante nesta fase de montagem da administração republicana, organização das bases de poder, elaboração da Constituição e dos regulamentos gerais, tendo oportunidade de defender e aplicar muitos dos princípios alimentados nos tempos de propaganda republicana, principalmente estes: descentralização dos serviços públicos, autonomia federativa, harmonia entre o Legislativo e o Executivo, direitos civis, regularização e controle das finanças públicas etc. Confrontado com os demais participantes desta Assembléia, Alberto Torres sobressai-se como político, impondo sua opinião (que se confundia com a do próprio Governo) quando se tratava de matérias especificamente de ordem político-administrativa. Quase não se envolve nos debates atinentes a problemas relacionados mais diretamente com a lavoura, a falta de braços, colonização, imigração, que eram preocupação de deputados vinculados estreitamente aos interesses agrários. A tônica dos discursos de Alberto Torres está no esforço de consolidar as forças republicanas, conciliar as divergências, restaurar o prestígio do Governo Estadual e do Governo Federal (Marechal Floriano) abalado com as crises políticas e levantes militares, depositar confiança e apôio nos oficiais e nas forças legalistas do Exército, sustentar o entusiasmo patriótico dos "cidadãos fluminenses", incita-los à defesa organizada e até armada das instituições e do governo republicano.

Por ocasião de um levante militar ocorrido em 14 de dezembro de 1892, em Niteroi, este representante do governo, convicto de que "as liberdades não se conseguem senão com a construção ordeira", pro- 
clama um discurso vasado numa linguagem carregada de tom emotivo, consagrando a divisão entre o bem e o mal, a ordem e a desordem. De um lado, as forças da "desordem": "o levante audacioso de meia dúzia de anarquistas", "a tentativa criminosa de um punhado de bandidos", "essa miseravel revolta de interesses e de ambições" - "ambições que subiam desde a aspiração mesquinha da soldadesca infrene, da polícia embriagada, pela cupidez do acesso, até a aspiração de mando desses outros, indivíduos que agem com a chicana da alta politicagem", "horda de soldados embriagados sob a direção de um grupo de anarquistas sem consciência, sem escrúpulos, sem moral, sem patriotismo". De outro, as forças da "legalidade" e da "soberania popular": "a pertinácia patriótica dos brasileiros", "a direção dos patriotas competentes que conduzem as multidões e a opinião política que secunda a direção desses cidadãos", "o exército brasileiro, orgão legítimo das aspirações populares", "defensor do povo, advogado dos seus interesses e instrumento da lei e autoridades", "orgão da defesa para antepor a esses grupos sediciosos o heroismo de suas almas com todo o vigor de seu patriotismo sem contestação". Sob o lema de "construção" e "ordem", como garantia da "liberdade", assinalava o congraçamento dos republicanos:

"Sr. Presidente, eu tenho a fortuna, eu tenho a glória de pretender que nenhum Estado do Brasil apresenta perante a civilização universal um espetáculo idêntico àquele que nós apresentamos (apoiados); eu tenho a glória de pretender que nenhum território da Confederação Brasileira pode ufanar-se tanto como o nosso de, em plena obra de reconstituição da República, ver reunidos sob um único sentimento, dominados po: um exclusivo ideal, homens que provieram de todos os matizes, hoje unidos na communhão do amor da pátria, na idolatria pela República (Muito bem).

Sr. Presidente, que significa esta Assembléia, em face da organização actual da República Brasileira? Significa isto: o patriotismo agindo com a sua força poderosa, com a sua influência dominadora, superior a todas as contingências humanas, ligando-nos a todos, estabelecendo entre nós, que fomos outr'ora adversários de lutas às vezes levadas a extremos violentos, os laços que nos ligam em um pensamento comum, em uma aspiração única!

(Muito bem, muito bem). (7).

$\mathrm{O}$ entusiasmo e a plena identificação legalista, praticamente inevitáveis nesta fase dificil de consolidação do regime, foram ao longo de

(7). - Anais da Sessão Extraordinária da Assembléia Legislativa do Estado do Rio de Janeiro. Rio de Janeiro, Jornal do Commercio, 1893. p. 83. 
sua carreira política cedendo lugar a uma discreta decepção quanto às "virtudes" da República, outras vezes suscitando críticas aos costumes políticos, sem que isso significasse abandono dos compromissos formais de sustentar a todo o custo e necessariamente a sobrevivência do regime, com apôio irrestrito às autoridades constituidas.

O desempenho do mandato presidencial no Estado do Rio (1897 a 1900) levou-o a ter contato direto com o funcionamento da administração republicana, e a envolver-se nas tramas, composições e divergências partidárias dos novos dirigentes do poder estadual. Na Mensagem enviada à Assembléia Legislativa (em 1899) despoja-se, por um momento, de sua autoridade de Chefe do governo, e arvora-se na sua condição de "brasileiro que estremece a República e zeloso pelo futuro da Pátria", para advertir seus "conterrâneos" quanto à crise que ameaçava a República. Exalta a política de conciliação anunciada por Campos Sales, "a missão alevantada e patriótica a que se dedica o Dr. Campos Sales", confortado na segurança de que a Constituição estava "entregue a mãos amigas e leais". Mas via um obstáculo nesta causa de reconstituição: "o espírito de partido", "a balda mórbida do partidarismo, a preocupação bizantina de manter fileiras inflexivelmente arregimentadas em torno de fórmulas vagas, de interesses ocasionais, de antigas bandeiras políticas, de ódios e solidariedades, "interesses egoísticos e agitações estéreis". Só via duas correntes de opinião possíveis de arregimentar legitimamente: "a dos adeptos da Constituição e a dos revisionistas". Sua descrença na representatividade dos partidos existentes aparece enfática:

“... Qs partidos são forças accidentais e passageiras divididas pelos problemas da época; e o propósito de os eternizar põe em evidencia a hibridez desses agrupamentos que nem a doutrina nem o temperamento selecionou; em cada um dos quais se confundem demagogos e reacionários; dent 0 de cujos quadros há conservadores que se entregam a excessos de anarquia e de violência na luta pelos seus interesses e radicais que apregoam as virtudes do estado de sítio; agrupamentos, enfim, cuja única ação eficaz consiste em levantar contra os Poderes Públicos e os interesses vitais do país as suas combinações, os seus caprichos e os seus preconceitos, transfo:mando casos vulgares de administração em graves questões políticas e erguendo à altura de transcendentes problemas, questiúnculas de campanário (8).

Por outro lado, a experiência obtida no governo do Estado do Rio permitiu-lhe defrontar-se com as dificuldades em que se debatia

(8). - Mensagem do Presidente do Estado do Rio de Janeiro à Assembléia Legislativa, 1899. Rio de Janeiro, Pap. Jeronymo Silva, 1899, p. VI-VII. 
a lavoura do café, a braços com a crise de superprodução, queda de preços, esgotamento do solo, falta de capitais e recursos tecnológicos inadequados. A análise desta situação aflitiva, para as quais diversas administrações anteriores e posteriores à sua tentaram resolver, levou-o a tecer considerações sobre os efeitos prejudiciais de certas medidas adotadas, ou criadas a despeito delas, e que, a seu ver, representavam indesejáveis fatores de dissolução, desintegração, desequilíbrio, e privilégios: a imigração estrangeira e a colonização de terras por estrangeiros, a especulação financeira e comercial em detrimento da produção, o protecionismo industrial, a concentração urbana.

Especificamente, o recurso à introdução de imigrantes estrangeiros, a título de suprir a demanda de mão-de-obra barata e eficaz, the parecia dispendiosa para a economia nacional, inteiramente perigosa para a estabilidade social, e vencia na concorrência para os "trabalhadores nacionais", que seriam mais vantajosos para o Estado.

"A imig:ação oficial em regra, sem seleção, avo'uma as pequenas indústrias urbanas, cria turmas nômades de operários agrícolas, mas não dá produtores, na justa acepção econômica; e. feito o cálculo das despesas que custam ao Estado, da pressão com que os imigrantes pesam sobre a taxa de câmbio pela exportação de capitais, da porcentagem dos que ficam nos trabalhos produtivos e da colaboração com que concor:em para as crises de excesso da produção, creio que a economia do país não terá lucros a registrar na contabilidade desse tráfico (9). (...).

Vinha-lhe a propósito registrar o grau de prejuizo da imigração, mostrando os seus resultados no Estado de São Paulo, onde o expediente aparentava ter produzido os melhores êxitos.

"Um fato recente documenta esta afirmação - o exôdo de imigrantes do Estado de São Paulo.

E o operariado flutuante, boêmio, que produz sem fixar-se e sem consumir, que serviu a lavoura paulista na obra do aumento exagerado da produção do café; e no momento da crise emigra para outras regiões, onde novas indústrias oferecem melhores e mais fáceis proventos" (10).

Como foi visto até aqui, Alberto Torres sempre se caracterizou pelo empenho de "reconstituir" a ordem, de preferência pelos métodos conciliatórios, pacíficos e persuasivos, e se necessário recorrendo a

(9). 一 Idem, ibidem, p. XXXV.

(10). - Idem, ibidem, p. XXXV. 
enérgicos expedientes repressivos (institucionais ou policiais). Sua passagem na chefia do executivo fluminense foi marcada pelo cumprimento rigoroso dos requisitos inerentes às funções governamentais de preservar a ordem, segurança e tranquilidade, do cidadão, da população, da propriedade e do Estado.

Entretanto, é relevante registrar o momento em que a preservação da ordem política se apresenta como desdobramento da ordem sócio-económica, mais precisamente das relações sociais consideradas mais propícias à estabilidade de uma sociedade predominantemente agrária. O tema da polarização cidade-campo - tão insistentemente retomado e generalizado posteriormente no seu programa nacionalista - acha-se fundamente radicado tanto nas idéias quanto em sua prática política. Pode ser localizado, inclusive, em atitudes mais remotas ainda, quando se discutiu na Assembléia Legislativa Estadual, em janeiro de 1893, a localização da capital do Estado em outra cidade, longe da influência política e das agitações sociais da grande cidade (Rio de Janeiro), impregnada de fatores dissolventes ("populações agitadas", "correntes de opiniões violentas, oriundas de tendências demagógicas, mas nascidas no seu próprio território") e onde a "ação plutocrata do grande centro comercial do Rio de Janeiro" ameaçava limitar a autonomia política de Niteroi. E na própria cidade de Niteroi, não via condições para servir de centro político, por seus "destinos de cidade comercial", "destinada a ser dentro em pouco uma das grandes metrópoles da indústria neste país", "esta cidade que hoje já é um centro operário", e onde, consequentemente, "as lutas que as capitais hão de trazer perturbação, pelo contrário, a evolução e o progresso de sua vida econômica e industrial" (11).

Agora, quando se acha investido da autoridade de Presidente, a sua responsabilidade obriga-o a encontrar a correção para os "males da sociedade" e os desvios no funcionamento do regime. O administrador apega-se, então, a uma solução de extrema urgência, a única capaz de reconstituir a unidade social: a educação, pela regeneração do carater, para formar a nacionalidade, mediante a criação de uma "força intelectual e moral que forma a corrente da opinião, indispensavel às civilizações modernas, para produzir a atmosfera moral e intelectual da Nação".

"Educar, é a primeira, a mais imperiosa das necessidades do nosso pais. Educar, estabelecendo o equilíbrio indispensavel entre o desenvolvimento físico, moral e intelectual de cada indivíduo; educar, para desenvolver e corrigir as faculdades naturais do

(11). - Anais da Assembléia Legislativa do Estado do Rio de Janeiro. Rio de Janeiro, Jornal do Commercio, 1893. p. 36. 
homem brasileiro; educar, para aperfeiçoar os estímulos e retificar os defeitos com que as condições da herança e do meio modelam os filhos da nossa teria; educar, enfim, para fazer a cultura do sentimento, do espírito e do carater nacional, de forma a constituir com a unidade das idéias e dos móveis morais e intelectuais, a mais sólida força da unidade da Pátria.

É preciso educar; é preciso que neste momento angustioso da nossa yida pública, em que todos os problemas, analisados nas suas fontes mais profundas, vão encontar como causa pertubadora uma ciise moral e social: a crise econômica e financeira, pelo sacrifício das ambições simples e produtivas à febre vertiginosa da especulação; a crise política, pelo esquecimento do dever cívico e pela esterilidade das lutas pessoais - é preciso que o esforço, a inteligência e o patriotismo dos homens públicos se concentrem na educação" (12).

A validade do programa pedagógico-civilizador atendia a uma outra estratégia: preservar a ordem social ("unidade nacional") das "ameaças externas".

"Os povos novos como o nosso, formados por camadas que se constituem rapidamente, à mercê das invasões colonizadoras, têm a sua unidade moial ameaçada pelos mais rudes embates.

Devemos por isso mesmo criar, com a resistência educativa, uma corrente tão forte de unidade que oponha a cada onda de imigração uma barreira espiritual possante, constituida pelo conjunto de sentimentos e ideais, que inspiraram a formação da nossa Pátria, na continuidade da raça a que pertencemos" (13).

No fundo, a base desse programa de reforma educacional correspondia a uma decepção com o funcionamento das instituições republicanas, mais particularmente com as atitudes dos grupos dirigentes, resultando na amarga constatação de que a sociedade não obtivera o "progresso" almejado nas lutas pela implantação da República.

Já um pouco antes, em 1894, o então deputado federal extravazava sua crítica aos costumes políticos, aos métodos broncos, violentos e atrasados dos dirigentes republicanos, através de uma série de crônicas diárias no jornal $A$ Notícia (14).

(12). - Mensagem do Presidente do Estado do Rio de Janeiro à Assembléia Legislativa, 1899. p. XXVIII.

(13). - Idem, ibidem, p. XXIX.

(14). - A Notícia, Rio de Janeiro, abril-dezembro 1895. A coluna vinha assinada por suas iniciais: A.T., e nela o antigo polemista da propa- 
Aliás, esse desencanto de Alberto Torres não era um caso isolado, pois, cumprida a missão de propagar, implantar e consolidar a República, não havia mais lugar para os reformadores. Alem disso, no plano das relações políticas e na montagem das estruturas de poder, o desencanto extrapolava a questão da esterilidade doutrinária e assumia o carater de lutas, dissidências, cisões, guerras particulares, disputas eleitorais, polarizações partidárias, assembléias duplas, todas as modalidades de divisões no interior das classes dominantes (econômica e politicamente), sobretudo em âmbito local e regional, que compuseram a evolução do regime republicano.

Os sinais desses desencanto passaram a constituir um traço de comportamento de jornalistas, intelectuais, representantes políticos, que alardeavam publicamente irresponsabilidade pelos acontecimentos, imparcialidade, descompromisso, patriotismo, etc. Nas suas manifestações públicas, Alberto Torres empenhou-se incansavelmente em justificar-se perante seus compatriotas e concidadãos, isentando-se dos "males" cometidos pelos republicanos, e alardeando virtudes cívicas e patrióticas. Recolho algumas dessas auto-justificativas, uma de 1911, outra de 1916, onde apresenta um verdadeiro memorial de sua carreira.

\footnotetext{
"Sem ambições políticas, servi ao regimem de que fui propagandista à força de responsabilidade por crenças a que havia dedicado as energias de moço; e me fui vendo ascender, de posição em posição com a frieza, quase com a insensibilidade pessoal com que se aceitam encargos que não são eleitos pelas nossas preferências, por nossos estudos e gostos intelectuais. Privilegiado como poucos pela fortuna política, jamais senti o prazer de amor próprio e as satisfações de glória que a carreira costuma conferir. E que eu não segui a minha carreira, não tive mesmo uma carreira; fui tudo quanto não merecia ser, mas tambem tudo quanto não ambicionei" (15).
}

O outro exemplo é de 1916, num dos costumeiros balanços da sua própria vida:

ganda valia-se de sua ironia, erudição jurídico-política e vivência parlamentar para comentar os assuntos do momento (debates na Câmara, leis, acontecimentos, homenagens, celebrações, Revolução Federalista, eleições, etc.) . Cabe registrar que essas crônicas foram descobertas por Dalmo Barreto, pesquisador da obra jornalística de Alberto Torres. Ver BARRETO, D. - ob. cit., p. 61-66).

(15). - Discu:so de posse no I.H.G.B. Revista do Instituto Histórico e Geográfico Brasileiro, 74 (124): 548, 1911. 
"Durante todo o longo decurso da minha carreira política - afirmo-o sem receio da mais completa análise e da mais ampla discussão - estou certo de que não se encontram nos meus atos, nas minhas palavras e nas minhas abstenções, nenhuma responsabilidade pelas causas da ruina das finanças públicas, da desordem, dos erros e da anarquia da política e da administração, do nosso miseravel estado de pobreza econômica - só disfarçada, nos centros onde se fazem negócios, pelos abusos da "exploração", que se tomam por progresso e enriquecimento nacional - como, pelo contário, posso apontar em meu passado, com relação a cada um dos artigos de acusação contra o regime e contra os seus homens, palavras e atos de advertência, de protesto e de reação, inúmeras iniciativas de previdência, de esclarecimento e de correção, contra lacunas, desvios, abandonos e descuidos, relativos a objectos vitais da nossa constituição e do nosso desenvolvimento. (...)

(...) quando fora das posições oficiais - posições que jamais ambicionei, jamais pleiteei e jamais conservei em detrimento do meu dever, que repeli e a que renunciei quando incompatíveis com a consciência das minhas responsabilidades - nunca fui elevado às comissões políticas que exerci, senão por escolha absolutamente espontânea dos meus chefes e dos meus correligio nários" (16).

Terminado o mandato presidencial em 1900, encerra-se tambem a carreira político-representativa de Alberto Torres. Sua ligação com o aparelho de Estado e com a própria política se fará em outros moldes, menos envolvidos com a prática política de assumir cargos de representação e governo. Torna-se funcionário do governo, nos quadros da alta Magistratura: Ministro do Supremo Tribunal Federal, onde permaneceu de 1900 a 1909, aposentando-se por motivos de saude em setembro de 1909. Pelo menos até 1907, quando voltou a colaborar na imprensa e empreendeu viagem à Europa, sua atuação intelectual esteve absorvida pelas questões jurídicas e, por esse motivo, não constituem objeto de interesse no momento (17).

Os anos que vão de 1907 a 1910 delimitam um período decisivo na trajetória republicana de Alberto Torres. Reatando seus vínculos originários com a imprensa, onde mais se realizava sua tendência de

(16). - Marcando os Passos. O Imparcial, 15/4/1916.

(17) - - De resto, a importância da passagem de Alberto Torres no Supremo Tribunal Federal já foi avaliada por estudiosos competentes na matéria: LIMA Sobr. (Barbosa), ob. cit., cap. 19, e principalmente, RODRIGUES (Leda Boechat), História do Supremo Tribunal Federal. Rio de Janeiro. Civilização Brasileira, 1968. v. II, pp. 38-40, 64, 94-98. 
"reformador", foi convidado em abril de 1907, pelo diretor do poderoso orgão da grande imprensa carioca, $O$ País, para colaborar numa coluna diária ("Tópicos do dia"). De abril a agosto de 1907 escreveu copiosamente sobre assuntos e temas variados, aproveitando em grande parte as notícias, as questões e os fatos comentados pelo próprio jornal, numa perfeita sintonia com a linha da redação. Em torno dos debates da Segunda Conferência de Haia, que enchiam as páginas dos jornais e nutriam os escritos de comentaristas e redatores, o experimentado Juiz do Supremo Tribunal pode exercitar sua erudição no "direito internacional" e discorrer sobre temas essenciais na argumentação estritamente jurídica, e certas ligações básicas entre o poder internacional e a política econômica, as relações internacionais e as relações econômicas, a conduta dos dirigentes políticos e a organização social e, no limite, alguns esboços sobre o estágio de desenvolvimento da sociedade capitalista industrial. A discussão da possibilidade de paz, de arbitramento, de equilíbrio entre as potências, suscita a necessidade de defrontar-se com questões mais relevantes: imperialismo, interesses econômicos, partilha colonial, corrida armamentista, desigualdade social, doutrinas racistas e militaristas.

E com esta temática vertida nos "Tópicos do dia", mais algumas leituras de obras de autores "pacifistas" europeus e norte-americanos, que reuniu material para a publicação de seu primeiro livro, Vers la paix, em 1909, após regressar da Europa (18).

A partir daí, explora diversos ângulos e implicações da doutrina "pacifista", cerceando gradativamente a natureza do "problema mundial", na busca de compreensão das origens e dimensionamento das soluções dos conflitos. E num desses ângulos depara com o "problema nacional", os impasses e as perspectivas específicas que estavam reservadas aos paises novos.

(18). - Na segunda edição do livro, preparada em 1913, mas só editada em 1927, por iniciativa de Roquete Pinto, Alberto Torres explicita no Prefácio sua filiação ao "pensamento pacifista", citando as obras de: Norman Angell, The Great Illusion; D.J. Hill, L'Etat Moderne et l'Organisation Internationalle; D.J. Staer, La Moisson Humaine, in Revue Internationalle de Sociologie; Léon Bourgois, Pour la Société des Nations; Novicow, Le Darwinisme Social et la Morale et l'Intérêt; Olphe-Galliard, La Morale des Nations Contemporaines; B. Secrigny, Les Conséquencse Sociales et Economiques de la Prochaine Guerre; Sir Thomas Barclay Problems of International Practice and Diplomacy; William Hull, The two Hague Conferences and their Contribuition to International Law. Muitas dessas ob:as apareceram depois de 1909; po:tanto, não podiam ter sido incorporadas na primeira versão, mostrando apenas pontos de afinidades, como no caso do livro de Norman Angell, que surgiu em 1910. A este respeito, Barbosa Lima Sobrinho, ob. cit., cap. 22, fornece informações esclarecedoras. 
Com esta preocupação desenvolve um esboço sintético da evolução histórica das civilizações, por ocasião de sua posse no Instituto Histórico e Geográfico Brasileiro, em 24 de julho de 1911 (19). As teses apresentadas no ambiente solene e acadêmico do Instituto, mais alguns estudos publicados na imprensa entre 1910 e 1912, serviramlhe de inspiração para escrever outro livro, acrescentado de maiores explanações e atualização bibliográfica, publicado em 1913: Le problème mondial. Tal como o Vers la paix, este livro é escrito em francês; não visava alcançar o público brasileiro, onde supunha inexistir o problema da guerra e imperar o temperamento pacifista (20).

A concentração de suas preocupações, nesses dois livros, com os problemas internacionais, significava uma tentativa de analisar a corrida armamentista e o expansionismo imperialista como efeitos de transformações sociais e econômicas que alteraram o equilíbrio interno das sociedades e, consecutivamente, das relações entre as nações.

A postura nacionalista, derivada da articulação entre os problemas externos é internos, define-se claramente em 1910, quando redige artigos de grande repercussão no Jornal do Commercio e na Gazeta de Notícias, dois influentes jornais da imprensa do Rio de Janeiro. Sob o impacto das tensões internacionais, da campanha civilista, e da vitćria do Presidente Hermes da Fonseca, elabora o corpo de suas

(19) . - Discurso de posse no I.H.G.B.. Revista do Instituto Histórico e Geográfico Brasileiro. 74 (124): 546--601, 1911.

(20). - Le Problème mondial procura rebater as teorias da superioridade racial e do expansionismo imperialista-militarista, apoiado em argumentos e comprovações de estudos sociológicos, filosóficos e, sobretudo, etnológicos, bastante atualizados. Por isso, é farto em citações de Autores e referências bibliográficas, esclarecendo as "influências" e "opções" de suas idéias. Às vezes, consagrando uma tradição acadêmica da época, simplesmente faz alusão ao nome de um Autor: Giddings, Lester Ward, Comte, Buckle, etc. No mais, dá referências um pouco mais detalhadas. Bergson, L'évolution creatice, W. Ostwald, Les fondements énergetiques de la science de la civilization; Hobhouse, Morals in evolution; Wheeler, The tribal and intertribal relations in Australia Man, 1951, 15. Grubb, An unknown people in an unknown land. Man, 1911, 57; Ratzel, The history of mankind; J. Finot, Le préjugé des races; Vacher de Lapouge, Les sélections sociales; E. Faguet, Le pacifisme; Gomperz, Les penseurs grecs; F.R. Farnell, The evolution of religion; P. Janet, Histoire de la science politique; E. Renan, Les origines du christianisme; Le Dantec, L'égoisme seule base de toute societé; $\mathbf{E}$. Rignano, On the menmonic origin and nature of affetive tendencies. "The Monist", 1911; W. Driesch, Encyclopaedia Britannica, 11a. ed., v. "cytology"; P. Kropotkine, Inheritance of acquired characters. Ninentienth century and after, 1912; Delage et Goldsmith, Les théories de l'évolution, avec les plus éminentes biologistes contemporains; $\mathrm{F}$. Nietzche, Le crépuscule des idoles; E. Réclus, L'Homme et la terre; J. de Gaultier, Mercure de France, 1912: La presomption sociologique; R. de Gourmont, Mercure de France, Une loi de constance intellectuelle; Les Annales Politiques et Littéraires.

Observação: estas referências foram transcritas lite:almente do livro citado. 
obras mais conhecidas, $A$ organização nacional e $O$ problema nacional brasileiro, ambas compostas quase que na íntegra desses artigos, $\mathrm{e}$ impressas em 1914 (21).

Afastado dos cargos públicos desde 1900 e aposentado do Supremo Tribunal desde 1909, entrega-se exclusivamente à elaboração de um programa de reformas ("revisão constitucional"), participando intensamente de diversos periódicos da imprensa carioca. Sem filiar-se diretamente a nenhum partido ou fração partidária, sua crítica se enquadra nos papeis de oposição aos governos vigentes, pelo simples fato de postular modificações na Constituição, e mais precisamente por rcjeitar métodos de política econômica, ação administrativa, mecanismos de representação, entre outras modalidades do funcionamento do regime republicano, conforme a orientação dos grupos dirigentes. De 1914 a 1916, realizou uma autêntica batalha na imprensa, sobretudo em jornais de pequeno porte, identificados um pouco mais ou menos com grupos políticos da oposição ( $O$ Imparcial, $A$ Noite e $A$ Tribuna) alargando e reiterando suas teses reformistas, e só interrompida com o agravamento de seu estado de saude no começo de 1917 (morreu em 29 de março de 1917).

Nesta fase final de sua trajetória, compreendida claramente entre 1909 e 1916, com alguns momentos decisivos, é sensivel o grau de aprofundamento e alargamento da temática liberal-democrática, pela incorporação de certos efeitos sociais de transformações e mudanças no sistema capitalista (em geral), com suas articulações na organização social nacional (Brasil). Sem configurar uma ruptura com as premissas liberais (mesmo no âmbito da ação política, situa-se na oposição dentro das estruturas de poder), houve maior aproximação com as fontes do poder, permitindo colocar em segundo plano a representatividade adequada dos "cidadãos" (forma de governo ou de regime), tão enfaticamente projetada inicialmente. Não que a questão da "forma de governo" tenha sido abandonada, pois o esforço da doutrinação nacionalista converge para a solução jurídico-política (revisão constitucional e ação política). Retrazendo a trilogia conceitual básica do programa liberal ("povo", "sociedade", "nação"), verifica se o privilegiamento da "organização" desses grandes fatores de reprentatividade. Se antes o que gerava o impasse era o "povo desgorvenado", agora adquiria mais peso o dilema da "desorganização" do "povo", da "sociedade" e da "nação". A legitimidade do poder vincula-se não apenas à consagração dos direitos e dos interesses "populares" ("povo",

(21). - A série de comentários ao programa do Marechal Hermes, lançada em 1910 e começo de 1911 na Gazeta, sob o título, "Á Margem de um manifesto", constitui a primeira seção de $A$ organização nacional. Já alguns artigos vindos originalmente no Jornal do Commercio, em 1912, formarão com modificações e acréscimos, os capítulos de $O$ problema nacional. 
"classes", cidadãos" “opinião", "patriotas", "indivíduos"), mas pela sua capacidade de abranger os "interesses nacionais", que passam a englobar e predominar sobre os demais. Daí poder falar-se de programa liberal-nacional. A identidade liberal manteve-se pela própria preservação dos direitos civis, dos jundamentos institucionais e, de certo modo, dos mecanismos representativos. Introduziram-se objetivos mais amplos (a "nação") e, para tanto, implicando em organização mais concentrada do poder (limitando a descentralização democrática irrestrita), ampliação das funções de Estado ("governo forte"), incorporação de reivindicações sociais ("questão social"), representação profissional nas Assembléias, delegação de poderes por vias indiretas ("elites dirigentes" e orgãos burocráticos).

E nessa fase de "construção" da nação, através de um programa tipicamente liberal-nacional, que se constituem as idéias e as atitudes básicas de sua ideologia nacionalista, apresentada sob a forma de conhecimento da "realidade" brasileira, crítica da situação vigente e proposta de solução mediante a aplicação de reformas adequadas à singularidade nacional.

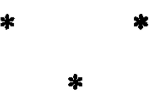

ADALBERTO MARSON. - Nasceu em Cajobí (SP) e fez o curso secundário nas cidades de Olímpia, Franca e São José do Rio Preto. Bacharel e Licenciado em História, pela Faculdade de Filosofia, Ciências e Letras da Universidade de São Paulo, em 1968. Recentemente, obteve o título de Doutor, sob orientação do Prof. Dr. Carlos Guilherme Mota. Lecionou as matérias de História do Brasil e História Geral no Curso de preparação aos vestibulares do Grêmio da Faculdade de Filosofia, Letras e Ciências Humanas da Universidade de São Paulo e no Equipe Vestibulares. Professor-Instrutor de História Ibérica da Faculdade de Filosofia Ciências e Letras de Assis (1970-1971). Instrutor-voluntário (1969) e, posteriormente Professor Colaborador (Auxiliar de Ensino) do Departamento de História da Faculdade de Filosofia, Letras e Ciências Humanas da Universidade de São Paulo, junto às disciplinas de História Moderna e Contemporânea, desde 1970.

Publicações: Resenhas na Revista de História, Anais de História (Assis), Suplemento Literário de $O$ Estado de São Paulo. Artigos sobre temas ligados à história política da República, ao nacionalismo, ao modernismo e à urbanização (em Alberto Torres), na Revista de História, Ciência e Cultura e Anais do VII Simpósio da ANPUH. A tese de Doutoramento intitula-se $A$ ideologia nacionalista em Alberto Torres. 